\title{
Frontonasal dysplasia-alopecia-genital anomalies syndrome
}

INSERM

\section{Source}

INSERM. (1999). Orphanet: an online rare disease and orphan drug data base.

Frontonasal dysplasia-alopecia-genital anomalies syndrome. ORPHA:228390

Frontonasal dysplasia with alopecia and genital anomaly is a new phenotype of frontonasal dysplasia associated with total alopecia and hypogonadism. 